\title{
Parental smoking and respiratory illness in infancy
}

\author{
D M FERGUSSON, L J HORWOOD, AND F T SHANNON
}

Christchurch Child Development Study, Department of Paediatrics, Christchurch Hospital, Christchurch, New Zealand

SUMMARY The relationship between parental smoking and respiratory illness in a birth cohort of 1180 one-year-old children was examined. Maternal smoking was associated with an increased incidence of lower respiratory illness but there was no statistically significant association between paternal smoking and lower respiratory illness. While children of mothers who smoked suffered more lower respiratory illnesses, their overall risk of respiratory infection was similar to that for children of nonsmoking mothers. The association between maternal smoking and infantile lower respiratory illness persisted when the child's social background, perinatal history, and postnatal diet were taken into account. The findings favour the view that prolonged exposure to cigarette smoke predisposes infants to develop lower respiratory symptoms when they contract a respiratory infection.

A number of studies has shown that parental smoking is related to an increased risk of bronchitis and pneumonia among children under one year ${ }^{1-2}$ and to an increased risk of morning cough and breathlessness among schoolchildren. ${ }^{3-6}$ The association between parental smoking and lower respiratory illness in children has been shown to persist when factors-such as, family size, birthweight, social class, the child's smoking habits-are taken into account. ${ }^{1-26}$ This paper examines the effects of parental smoking on the risk and nature of respiratory illness during the last 8 months of the first year of life in a birth cohort of 1180 infants.

\section{Method}

The data were collected during the third stage of the Christchurch Child Development Study. ${ }^{7}$ In this project a cohort of infants was studied at birth, at 4 months, and one year. At birth, the child's mother was interviewed, using a structured schedule, to find out the background to the pregnancy and the antenatal history. When the child was $\mathbf{4}$ months old, the mother was again interviewed, using a structured schedule, to find out about the child's health and development since birth, the diet, and the social and economic background of the family. At one year a similar interview was administered. At each inter-

Department of Paediatrics, Christchurch Hospital, New Zealand

D M FERGUSSON, principal investigator

L J HORWOOD, research assistant

F T SHANNON, professor of paediatrics view the mother signed a consent form indicating her willingness to participate in the research.

The initial cohort comprised 1262 children and one year later 1180 were still in the study. This represented $94 \%$ of the initial cohort and $97 \%$ of the children who were still alive and resident in New Zealand. The following measures were used in the analysis.

Measures of respiratory illness. To measure respiratory illness, both that involving medical consultation and that treated at home, two measures of respiratory illness were constructed.

\section{Medical consultation}

At 4 months and again at one year the child's mother was asked to give details of the child's history of medical consultation. While maternal reports of medical consultation are unlikely to be completely accurate, Colley ${ }^{5}$ found there was good agreement between such reports and medical records. From the maternal reports of medical consultation, a child was defined as having a lower respiratory illness if he had attended a medical practitioner or a hospital for bronchitis, bronchiolitis, or pneumonia. A child was defined as suffering an upper respiratory illness if he had attended a medical practitioner or hospital for respiratory illness other than bronchitis, bronchiolitis, or pneumonia.

\section{Symptoms}

To supplement the data on medical consultations each mother was asked whether the child had 
displayed any of a series of respiratory symptoms, irrespective of whether he had seen a doctor. From this questioning two measures were constructed. The first was whether the child had ever suffered a 'wheezy chest' and the second was whether he had ever suffered other respiratory symptoms such as cold, sore throat, sore ears, etc. Questioning on symptoms was only conducted at one year, so that complete medical data on the child were available only for the period from 4 months to one year. Because of this, the analysis is restricted to the last 8 months of the child's first year of life.

Parental smoking. Parents were classified as 'smoker' or 'nonsmoker'.

Perinatal history, social background, and diet measures. The following variables were used in the analysis for purposes of statistical control: birthweight, gestational age, maternal age, maternal education, maternal race, number of children in the family, family living standards, and duration of breast feeding.

The joint effects of maternal and paternal smoking on the risk of lower respiratory illness were analysed using the logistic analysis of factorial designs described by Cox. ${ }^{8}$ In this analysis maternal and paternal smoking were treated as two factors and the proportion of infants with lower respiratory illness was the dependent variable. This proportion was transformed using the logistic function and contrasts of the effects of maternal smoking, paternal smoking, and the maternal/paternal smoking interaction were examined.

\section{Results}

Tables 1 and 2 show the relationship between parental smoking and the risk of medical attendance for lower respiratory illness, and maternal reports of wheezy chest during the last 8 months of the first year of life. The risk of lower respiratory illness

Table 1 Percentage of children with medical consultation for lower respiratory illness by parental smoking*

\begin{tabular}{llll}
\hline Father & \multicolumn{2}{l}{ Mother } & \\
\cline { 2 - 4 } & Nonsmoker & Smoker & Overall \\
\hline Nonsmokert & 6 & 10 & 7 \\
& $(\mathrm{n}=588)$ & $(\mathrm{n}=190)$ & $(\mathrm{n}=778)$ \\
Smoker & 6 & 14 & 10 \\
& $(\mathrm{n}=192)$ & $(\mathrm{n}=199)$ & $(\mathrm{n}=391)$ \\
Overall & 6 & 12 & 8 \\
& $(\mathrm{n}=780)$ & $(\mathrm{n}=389)$ & $(\mathrm{n}=1169)$ \\
\hline
\end{tabular}

* Excludes 11 children for whom data were missing for either smoking or respiratory illness.

†Includes 88 families in which there was no father, or father figure.
Table 2 Percentage of children with wheezy chest by parental smoking*

\begin{tabular}{|c|c|c|c|}
\hline \multirow[t]{2}{*}{ Father } & \multicolumn{3}{|l|}{ Mother } \\
\hline & Nonsmoker & Smoker & Overall \\
\hline Nonsmoker $†$ & $\begin{array}{l}29 \\
(n=588)\end{array}$ & $\begin{array}{l}38 \\
(n=190)\end{array}$ & $\begin{array}{l}31 \\
(n=778)\end{array}$ \\
\hline Smoker & $\begin{array}{l}30 \\
(n=192)\end{array}$ & $\begin{array}{l}43 \\
(n=199)\end{array}$ & $\begin{array}{l}36 \\
(n=391)\end{array}$ \\
\hline Overall & $(n=780)$ & $\begin{array}{l}40 \\
(n=389)\end{array}$ & $\begin{array}{l}33 \\
(n=1169)\end{array}$ \\
\hline
\end{tabular}

*Excludes 11 children for whom data were missing for either smoking or wheezy chest.

†Includes 88 families in which there was no father, or father figure.

varied with parental smoking: children from families in which both parents smoked had over twice the risk of medical attendance for lower respiratory illness and 1.5 times the risk of a maternal report of wheezy chest compared with children from nonsmoking families.

Examination of the effects of maternal and paternal smoking on the risk distributions for both measures showed: maternal smoking was related to an increased risk of lower respiratory illness $(P<0 \cdot 001)$; there was no significant association between paternal smoking and lower respiratory illness $(P>0.05)$; there was no significant interaction between maternal smoking, paternal smoking, and the risk of lower respiratory illness $(\mathrm{P}>0 \cdot 05)$.

Table 3 shows the relationship between maternal smoking and the risk of all respiratory illness or symptoms. This risk is subdivided into upper respiratory illness or symptoms only (such as, nasal discharge, pharyngitis, otitis media, maternal reports of cold, sore throat) and lower respiratory illness or symptoms (such as, bronchitis, bronchiolitis, pneumonia, maternal reports of wheezy chest). Overall, the risk of respiratory illness was similar for the children of smokers and nonsmokers. However, the nature of the illness varied with maternal smoking: children of mothers who smoked had a greater incidence of lower respiratory illness or

Table 3 Percentage of children with respiratory symptoms, upper respiratory symptoms only, lower respiratory symptoms, by maternal smoking

\begin{tabular}{lllll}
\hline Measure & $\begin{array}{l}\text { Non- } \\
\text { smoker } \\
(n=786)\end{array}$ & $\begin{array}{l}\text { Smoker } \\
(n=394)\end{array}$ & $\begin{array}{l}\text { Total } \\
(n=1180)\end{array}$ & $P^{*}$ \\
\hline $\begin{array}{l}\text { With at least one } \\
\text { respiratory symptom } 91\end{array}$ & 93 & 92 & $>0.05$ \\
$\begin{array}{l}\text { With upper respiratory } \\
\text { symptoms only }\end{array}$ & 63 & 52 & 60 & $<0.001$ \\
$\begin{array}{l}\text { With lower respiratory } \\
\text { symptoms }\end{array}$ & 29 & 40 & 33 & $<0.001$ \\
\hline$\chi^{2}$ test. & & & &
\end{tabular}


Table 4 Risks of lower respiratory illness adjusted for perinatal factors, home background, and breast feeding

\begin{tabular}{|c|c|c|c|c|c|}
\hline \multirow[t]{2}{*}{ Measure } & \multicolumn{5}{|c|}{ Adjustment } \\
\hline & None & Perinatal history & Home background & Breast feeding & All factors \\
\hline $\begin{array}{l}\text { Medical consultatio } \\
\text { Nonsmoker (\%) } \\
\text { Smoker (\%) }\end{array}$ & $\begin{array}{r}6 \\
12\end{array}$ & $\begin{array}{r}6 \\
12\end{array}$ & $\begin{array}{r}6 \\
12\end{array}$ & $\begin{array}{r}6 \\
12\end{array}$ & $\begin{array}{r}6 \\
12\end{array}$ \\
\hline $\begin{array}{l}\text { Maternal reports of } \\
\text { Nonsmoker (\%) } \\
\text { Smoker (\%) }\end{array}$ & $\begin{array}{l}\text { ch chest } \\
29 \\
40\end{array}$ & $\begin{array}{l}28 \\
41\end{array}$ & $\begin{array}{l}29 \\
40\end{array}$ & $\begin{array}{l}29 \\
40\end{array}$ & $\begin{array}{l}29 \\
40\end{array}$ \\
\hline
\end{tabular}

symptoms but a lower risk of respiratory illness affecting only the upper respiratory tract.

To control for the effects of the child's perinatal history, home background, and postnatal diet, the binary multiple regression method described by Feldstein ${ }^{9}$ was used. Table 4 shows for the two measures of lower respiratory illness: (1) The risk of lower respiratory illness for children of smoking and nonsmoking mothers, adjusted for the effects of birthweight and gestational age. (2) The risk of lower respiratory illness for children of smoking and nonsmoking mothers, adjusted for the effects of maternal age, education, ethnic status, family size, and family living standards. (3) The risk of lower respiratory illness for children of smoking and nonsmoking mothers, adjusted for the effects of duration of breast feeding. (4) The risk of lower respiratory illness for children of smoking and nonsmoking mothers, adjusted for the joint effects of the perinatal, home background, and diet measures.

It can be seen from Table 4 that the adjusted estimates of the risks of lower respiratory illness do not differ appreciably from the unadjusted risks. This indicates that the apparent association between maternal smoking and infantile lower respiratory illness cannot be explained by the confounding effects of factors relating to perinatal history, home background, or postnatal diet.

\section{Discussion}

An association between parental smoking and infantile lower respiratory illness has been demonstrated. ${ }^{1-2}$ The findings reported here extend knowledge of this association in a number of ways.

Perhaps the most interesting result is that, while maternal smoking was associated with an increased risk of infantile lower respiratory illness, there was no such association for paternal smoking. This difference has been overlooked in previous studies which have not considered the sex of the smoking parent. The obvious implication of the result is that duration of exposure to cigarette smoke (rather than the presence of a smoker in the house) is an important factor in the correlation.
Previous studies have considered the effects of parental smoking on lower respiratory illness only. The findings reported here show that there is a complicated relationship between parental smoking and all respiratory illness. Overall, the children of mothers who smoke do not have a greater risk of respiratory illness but they do have a greater risk of suffering respiratory illness affecting the lower respiratory tract. This finding suggests that the effect of maternal smoking is to irritate the infantile lung and thus facilitate the spread of infection to the lower respiratory tract.

In addition, previous research has examined the relationship between parental smoking and medical consultation for lower respiratory illness. Since medical consultations probably provide a biased sample of infant illness, there is the possibility that the apparent association between parental smoking and infant lower respiratory illness could have arisen from some bias in consulting practices. The results reported here show that this is unlikely to be the case: an association between maternal smoking and infantile lower respiratory illness has been shown to exist both for illness needing medical treatment and for maternal reports of lower respiratory symptoms, irrespective of whether these symptoms were treated by a medical practitioner.

Finally, the range of social and perinatal factors controlled in this study is greater than that considered in previous studies of the topic. On the basis of the findings reported here, it may be concluded that the association between maternal smoking and infantile lower respiratory illness cannot be explained by the confounding effects of such factors as adverse perinatal history, depressed social background, or bottle feeding.

There now appears to be sufficient evidence to support the view that people in regular and prolonged contact with infants should not smoke, or if they must, they should not do so in the presence of infants.

This research was supported by grants from the Medical Research Council of New Zealand and the National Children's Health Research Foundation. 


\section{References}

1 Colley J R T, Holland W W, Corkhill R T. Influence of passive smoking and parental phlegm on pneumonia and bronchitis in early childhood. Lancet 1974 ; ii: 1031-4.

2 Harlap S, Davies A M. Infant admissions to hospital and maternal smoking. Lancet 1974; i : 529-32.

3 Cameron R, Kostin J S, Zaks J M, et al. The health of smokers' and non-smokers' children. J Allergy 1969; 43: 336-41.

4 Norman-Taylor W, Dickinson V A. Dangers for children in smoking families. Community Med 1972;128: 32-3.

5 Colley J R T. Respiratory symptoms in children and parental smoking and phlegm production. $\mathrm{Br}$ Med $J$ 1974; ii: 201-4.

- Bland M, Bewley B R, Pollard V, Banks M H. Effect of children's and parents' smoking on respiratory symptoms. Arch Dis Child 1978; 53: 100-5.
? Fergusson D M, Horwood L J, Wright R, Stewart C R. Factors associated with planned and unplanned nuptial births. NZ Med J 1978; 88: 89-92.

8 Cox D R. Analysis of binary data. London: Methuen, 1970.

- Feldstein M S. A binary variable multiple regression method of analysing factors affecting perinatal mortality and other outcomes of pregnancy. J Roy Stat Soc 1966; 129: 61-73.

Correspondence to $\mathrm{Mr} \mathrm{D}$ M Fergusson, Christchurch Child Development Study, Department of Paediatrics, Christchurch Clinical School of Medicine, Christchurch Hospital, Christchurch, New Zealand.

Received 19 June 1979 